\title{
REctus Sheath block for postoperative analgesia in gynecological ONcology Surgery (RESONS): a randomized-controlled trial
}

\section{Bloc de la gaine des grands droits pour une analgésie postopératoire en chirurgie gynéco-oncologique: RESONS, une étude randomisée contrôlée}

\author{
Sumitra G. Bakshi, MD • Amol Mapari, MD • T. S. Shylasree, MD
}

Received: 13 August 2015/Revised: 1 August 2016/Accepted: 19 August 2016/Published online: 14 September 2016

(C) Canadian Anesthesiologists' Society 2016

\begin{abstract}
Background Opioid-sparing pain management is important for Enhanced Recovery After Surgery. Rectus sheath (RS) blocks are emerging as a promising modality for pain relief following midline laparotomy; however, there are limited prospective clinical trials testing their efficacy. The purpose of this randomized-controlled trial is to assess the morphine-sparing effect of local anesthetic (LA) boluses through $R S$ catheters following elective gynecological oncology surgery.

Method After patients' informed consent, bilateral RS catheters were placed intraoperatively in 74 females (American Society of Anesthesiologists physical status I-II) undergoing elective midline laparotomy under general anesthesia. The patients were randomized to receive 20-mL injections of either LA $(0.25 \%$ bupivacaine $)$ or normal saline (NS) postoperatively every six hours for $48 \mathrm{hr}$. Groups were compared for the co-primary outcomes of
\end{abstract}

Previous presentation: This paper was presented and awarded the best free paper award at the free papers session at the Australian and New Zealand College of Anesthetists and Faculty of Pain Medicine (ANZCA-FPM) Annual Scientific Meeting, May 5-9, 2014, Singapore.

Disclosure: Financial support for this trial was provided by a grant from Tata Memorial Centre -Research Administrative Council (TRAC), Parel, Mumbai, INDIA.

S. G. Bakshi, MD $(\bowtie) \cdot$ A. Mapari, MD

Department of Anesthesia, Critical Care \& Pain, Tata Memorial

Hospital, Parel, Mumbai, India

e-mail: sumitrabakshi@yahoo.in

T. S. Shylasree, MD

Department of Gynecological Oncology, Tata Memorial

Hospital, Parel, Mumbai, India
24- and 48-hr morphine requirements. The secondary outcomes were numeric rating scale (NRS) scores for pain recorded at rest and with movement.

Results The mean (SD) morphine consumption was significantly reduced in the LA group compared with the NS group at $24 \mathrm{hr}[8.8$ (8.3) $\mathrm{mg}$ vs 27.3 (10.0) $\mathrm{mg}$, respectively; mean difference, $18.5 \mathrm{mg}$; $95 \%$ confidence interval (CI), 14.3 to 22.8; $P<0.001]$ and at $48 \mathrm{hr}[14.8$ (11.0) $\mathrm{mg}$ vs 42.4 (16.8) $\mathrm{mg}$, respectively; mean difference, $27.7 \mathrm{mg} ; 95 \% \mathrm{CI}, 20.9$ to 34.3; P<0.001]. At $48 \mathrm{hr}$ postoperatively, there was also a significant decrease in the median [interquartile range] NRS scores for pain in the LA group compared with the NS group, both at rest (3 [2-3] vs 5 [5-6], respectively; $P<0.001)$ and with movement (4 [4-5] vs 7 [6-8], respectively; $P<0.001)$.

Conclusion The use of intermittent LA boluses through RS catheters is an effective morphine-sparing pain management strategy for females undergoing midline laparotomy for gynecological cancer surgery. This study was registered with the Clinical Trial Registry of India (CTRI/2013/10/004075).

\section{Résumé}

Contexte L'épargne morphinique dans la prise en charge de la douleur est importante pour une Récupération rapide après la chirurgie. Le bloc de la gaine des grands droits constitue une modalité très prometteuse pour soulager la douleur après une laparotomie médiane; toutefois, peu d'études cliniques prospectives évaluent son efficacité. L'objectif de cette étude randomisée contrôlée est d'évaluer l'effet d'épargne morphinique de bolus d'anesthésique local (AL) administrés via des sondes dans la gaine des grands droits après une chirurgie gynéco-oncologique non urgente. 
Méthode Après avoir obtenu le consentement éclairé des patientes, une sonde bilatérale a été placée en peropératoire au niveau de la gaine des grands droits chez 74 femmes adultes (statut physique I-II selon l'American Society of Anesthesiologists) subissant une laparotomie médiane non urgente sous anesthésie générale. Les patientes ont été randomisées à recevoir des injections de $20 \mathrm{~mL}$ d'AL (bupivacaïne 0,25\%) ou de soluté physiologique (NS) en période postopératoire, soit toutes les six heures pendant 48 heures. Les groupes ont été comparés pour évaluer nos critères d'évaluation primaires conjoints, soit les besoins morphiniques à 24 et 48 h. Les critères d'évaluation secondaires étaient les scores de douleur enregistrés au repos et en mouvement sur une échelle d'évaluation numérique (EEN).

Résultats La consommation morphinique moyenne (ÉT) était significativement réduite dans le groupe $A L$ par rapport au groupe NS à $24 \mathrm{~h}[8,8(8,3) \mathrm{mg}$ vs 27,3 $(10,0)$ $\mathrm{mg}$, respectivement; différence moyenne, $18,5 \mathrm{mg}$; intervalle de confiance (IC) $95 \%, 14,3$ à 22,8; $P<$ $0,001]$ et à $48 h$ [14,8 (11,0) $\mathrm{mg}$ vs 42,4 (16,8) $\mathrm{mg}$, respectivement; différence moyenne, 27,7 mg; IC $95 \%$, $20,9$ à 34,3; $P<0,001]$. Quarante-huit heures après l'opération, on a également observé une réduction significative des scores de douleur médians [écart interquartile] sur l'EEN dans le groupe AL par rapport au groupe NS, tant au repos (3 [2-3] vs 5 [5-6], respectivement; $P<0,001$ ) qu'en mouvement (4 [4-5] vs 7 [6-8], respectivement; $P<0,001$ ).

Conclusion L'utilisation de bolus intermittents d'AL via des sondes placées dans la gaine des grands droits constitue une stratégie efficace de prise en charge de la douleur avec épargne morphinique pour les femmes subissant une laparotomie médiane dans les cas de chirurgie gynéco-oncologique. Cette étude est enregistrée dans le Registre des études cliniques indiennes (CTRI/ 2013/10/004075).

Effective management of postoperative pain following laparotomy is essential. In this era of Enhanced Recovery After Surgery (ERAS) programs, it has been shown that opioids have a considerable role in reducing bowel motility. ${ }^{1,2}$ Other side effects of opioids (e.g., nausea and vomiting) also hinder early mobilization and enteral feeding. ${ }^{3}$ Indeed, a corner stone of ERAS is the use of multimodal analgesia to provide effective pain relief while reducing opioid-related side effects. ${ }^{1}$

Epidural analgesia (EA) has remained popular with evidence of superior postoperative pain control when compared with systemic analgesics. ${ }^{4}$ Epidural analgesia may not be suitable for all patients, however, and failure rates are well known in both placement and delivery of adequate analgesia. ${ }^{4}$ In addition, complications from EA, though rare, can result in serious morbidity. ${ }^{5}$ Indeed, some published guidelines for abdominal hysterectomy do not recommend routine EA for use in low-risk gynecological operations as the risk of complications may outweigh the analgesic benefits in this group. ${ }^{6}$ Nevertheless, patients undergoing high-risk gynecological surgery (i.e., due to patient comorbidity or the need for extensive surgery due to malignancy) are excluded from this recommendation. ${ }^{6}$

Regional anesthesia techniques have undergone considerable refinement with the advent of ultrasound guidance. Ultrasound visualization of anatomical structures increases both the safety and quality of regional blocks through optimal needle placement. ${ }^{7}$ Ultrasound-guided rectus sheath (RS) blocks have gained popularity due to their relatively high rate of success and low rate of complications. ${ }^{8,9}$ Although large case series describe the use of RS blocks in gynecological cancer surgery and urological and colorectal surgeries, ${ }^{4,10-12}$ there is a paucity of randomized clinical trials evaluating this technique.

This purpose of this study was to assess the opioidsparing effect of RS blocks in the management of postoperative pain following midline laparotomy for gynecological cancer. We hypothesized that RS blocks would provide adequate pain relief in these patients when compared with a placebo group, and would therefore reduce the primary outcome of opioid consumption at 24 and $48 \mathrm{hr}$ after surgery.

\section{Method}

The study was approved in June 2013 by our Institutional Ethics Committee (IEC). Written informed consent was obtained from females aged 18-75 yr and American Society of Anesthesiologists physical status I-II undergoing elective midline laparotomy for gynecological cancer surgery. Exclusion criteria included refusal to consent, previous laparotomy (subsequently amended to exclude only a laparotomy with a paramedian scar), significant hepatic or renal disease, any condition limiting the use of co-analgesics (diclofenac and acetaminophen), coagulopathy (international normalized ratio $>1.5$ ), and patients with body weight $<50 \mathrm{~kg}$ (amended to exclude patients with body weight $<45 \mathrm{~kg}$ ). Both the amendments in the exclusion criteria were implemented to improve recruitment. These changes were approved by the IEC and put into effect after the first 28 patients were enrolled in the trial.

All patients who consented to participate were preoperatively educated in the use of patient-controlled 
analgesia (PCA) pumps and were familiarized with the use of the 0-10 numeric rating scale (NRS) (where $0=$ no pain and $10=$ worst pain imaginable) for their postoperative pain at rest and with movement. ${ }^{13}$ Intraoperative monitoring and management were standardized for all cases. ${ }^{14}$ Patients were induced with either propofol 2-3 $\mathrm{mg} \cdot \mathrm{kg}^{-1} i v$ or thiopentone sodium $5-7 \mathrm{mg} \cdot \mathrm{kg}^{-1} i v$, and neuromuscular blockade was maintained by an appropriate nondepolarizing agent. Fentanyl $2 \mu \mathrm{g} \cdot \mathrm{kg}^{-1}$ was given at induction, followed by morphine (up to $0.1 \mathrm{mg} \cdot \mathrm{kg}^{-1}$ ) iv after 30-45 min. At incision, acetaminophen 0.5-1.0 $\mathrm{g} i v$ was administered. Fentanyl $1-2 \mu \mathrm{g} \cdot \mathrm{kg}^{-1}$ could be repeated at the discretion of the anesthesiologist, if required. At completion of surgery and after checking for hemostasis, diclofenac $1 \mathrm{mg} \cdot \mathrm{kg}^{-1}$ (not exceeding $75 \mathrm{mg}$ ) iv and metoclopramide $10 \mathrm{mg} i v$ were administered.

During the abdominal wall closure, the surgeon inserted a 16G Tuohy epidural needle (Epidural Minipack; Smith Medical, Portex, UK) percutaneously $1 \mathrm{~cm}$ superior and 1 $\mathrm{cm}$ lateral to the upper end of the surgical wound. Using a "bimanual" palpation technique for needle placement, the surgeon inserted one hand through the open abdominal incision and used the other hand to guide the needle and position the needle tip beneath the rectus muscle (Fig. 1a). With the Tuohy needle in place, the anesthesiologist (scrubbed in for the procedure) confirmed the placement of the needle with a sterile ultrasound probe HFL38xp (13-6 $\mathrm{MHz}$ ) linear array transducer (M-Turbo ${ }^{\circledR}$ Ultrasound system; SonoSite, Bothell, WA, USA) (Fig. 1b) using uniform hydrodissection of the plane between the rectus muscle and posterior sheath. ${ }^{15}$ If the clinically placed needle was incorrectly positioned (Fig. 1c), the anesthesiologist manipulated the needle and placed it in the desired plane under ultrasound guidance (Fig. 1d). Any manipulation of the clinically placed needle under ultrasound guidance was recorded.

When the needle tip was correctly positioned, a16G closed-ended multiport nylon epidural catheter (Epidural Minipack; Smith Medical, Portex, UK) was threaded through the needle until 5-7 $\mathrm{cm}$ of the catheter's length was introduced into the RS space. The procedure was repeated on the other side. Following skin closure, the catheters were fixed using Steri-Strip ${ }^{\mathrm{TM}}$ adhesive skin closures (3M Nexcare ${ }^{\mathrm{TM}}$, USA) over which a sterile Tegaderm $^{\mathrm{TM}}$ dressing (3M Health Care, USA) was applied (Fig. 1e), and the four corners were reinforced with Micropore $^{\mathrm{TM}}$ surgical tape (3M Health Care, USA).

Once the rectus muscle layer was closed and as the skin was being stapled, $20 \mathrm{~mL}$ of the study drug $(0.25 \%$ bupivacaine or normal saline [NS]) were administered through each RS catheter. This point in time was noted as zero hour, and patients were then given the study drug (bolus) every six hours ${ }^{10}$ for the first $48 \mathrm{hr}$ thereafter. Only
$18 \mathrm{~mL}$ of study drug were administered to patients with a body weight of $45-50 \mathrm{~kg}$.

Randomization of patients to the LA or NS arm was in accordance with the sequence generated using Stata ${ }^{\circledR}$ version 11software (StataCorp; TX, USA). An independent group (two anesthesia residents) prepared the study drug for each group according to a code known to them alone. The residents, who were not part of the investigating team, performed the randomization and allocation, prepared labelled syringes of the study drug to be administered, and handed the applicable syringes to the investigators. Thus allocation concealment was assured, and the investigators and patients were blinded to the entire process of randomization and the nature of study drug.

In the postanesthesia care unit, a PCA pump with morphine was initiated with a standard setting of a 1-mg bolus and a lockout interval of ten minutes. In case of NRS pain scores $>3$, a morphine $2-3 \mathrm{mg}$ iv bolus was administered and pain was reassessed after 10-15 min. All patients received diclofenac $45-75 \mathrm{mg} i v$ every eight hours and an injection/tablet of acetaminophen $(>50 \mathrm{~kg}, 1$ $\mathrm{g} ; 45-50 \mathrm{~kg}, 750 \mathrm{mg}$ ) every six hours. Metoclopramide 10 $\mathrm{mg} i v$ was administered for the management of a single episode of severe nausea ( $>7$ on the nausea scale), for recurrent nausea, or for any episode of vomiting.

The primary aim of this study was to compare the morphine consumption between the LA and NS groups at the end of $24 \mathrm{hr}$, and as the RS infusions continued for 48 $\mathrm{hr}$, morphine consumption at the end of $48 \mathrm{hr}$ was also considered a co-primary endpoint. The secondary endpoints included a comparison between groups with regard to NRS scores (average pain and worst pain), time to first ambulation, and patient satisfaction scores at the end of $48 \mathrm{hr}$. An investigator blinded to group assignment performed pain assessments for all patients. The NRS score was recorded just prior to and two hours after each study drug bolus. Two hours postoperatively, all patients were instructed to cough, take deep breaths, and sit upright. After six hours, patients were actively encouraged to ambulate. At any assessment point, if the NRS score was $>$ 3 at rest or $>4$ with movement, a morphine bolus 2-3 mg was administered (referred to as the clinician's bolus). The time of first patient ambulation was recorded.

Other outcomes examined included the incidence of morphine-related side effects, including sedation, nausea scores, vomiting episodes, pruritus, and bowel activity (assessed by time to first passage of flatus). The level of sedation was assessed using the six-point Ramsay sedation scale (where $1=$ awake, anxious, agitated, restless and $6=$ asleep, no response to light glabellar tap or loud auditory stimulus). ${ }^{16}$ Nausea was assessed on a scale from $0-10$ (where $0=$ no nausea and $10=$ severe nausea). 

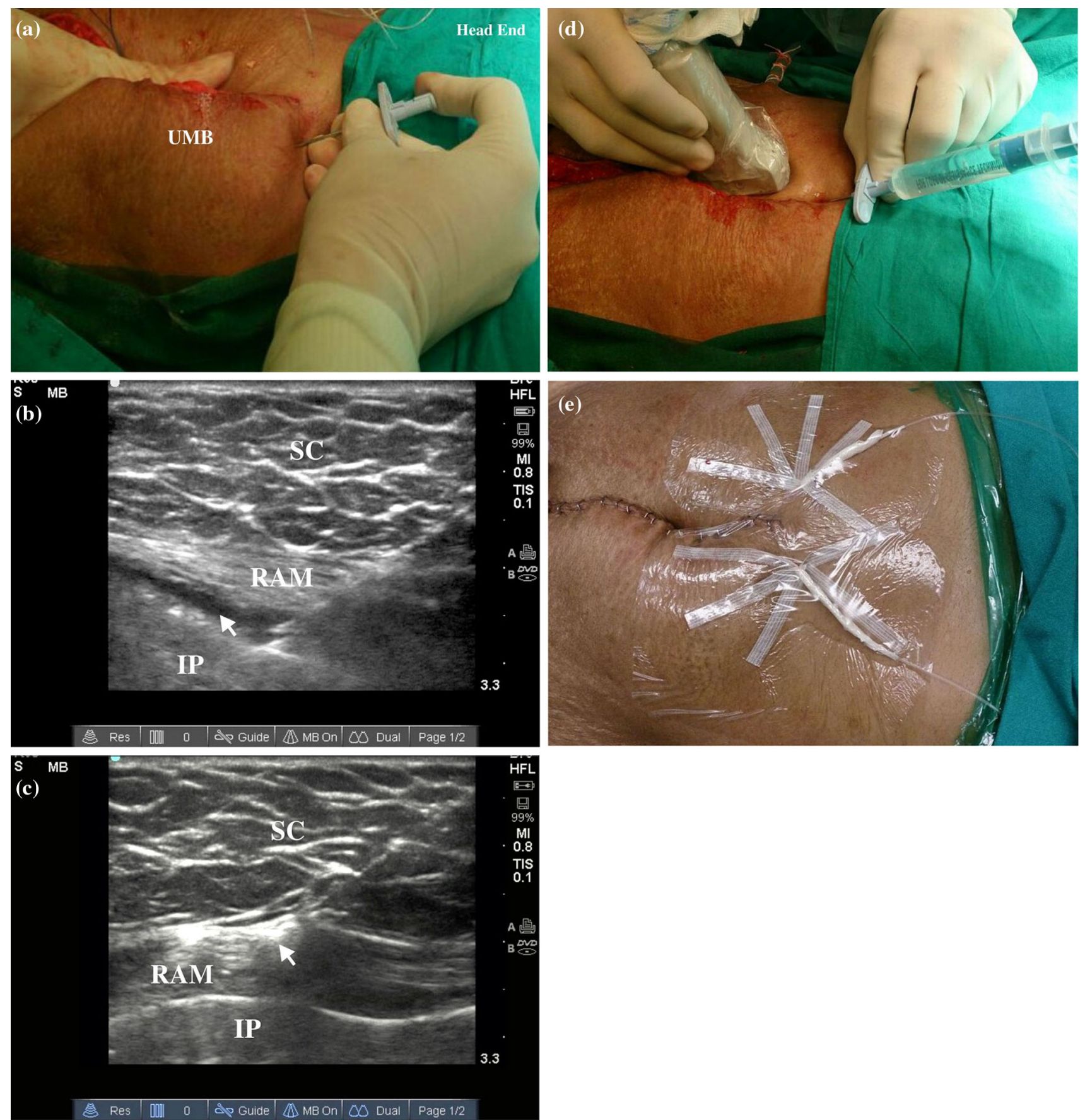

Fig. 1 a-e Illustrates the technique used for insertion of rectus sheath catheters. a Figure shows initial placement of Tuohy needle in the rectus space using bimanual palpation method. The needle is advanced by the dominant hand while the other hand, placed beneath the abdominal wall, guides the needle to its desired position-beneath the rectus muscle; $\mathrm{UMB}=$ umbilicus. $\mathbf{b}$ Ultrasound confirmation of correct needle placement in the rectus space: the uniform hydrodissection of the plane between the rectus muscle and posterior sheath confirms correct placement. c Figure depicts an inappropriate needle placement. The clinically placed needle tip is seen within the rectus muscle, which suggests an

incorrect placement. The needle was manipulated under ultrasound guidance to its correct placement. IP = intraperitoneal space; $\mathrm{RAM}=$ rectus abdominis muscle; $\mathrm{SC}=$ subcutaneous tissue; arrow shows tip of needle. d Manipulation of the needle under ultrasound guidance. The linear array probe is held vertically parallel to the incision so that the entire length of the needle can be visualized in an "in plane" view. The needle is now manipulated to its correct position (Fig. 1b), which is confirmed using saline. e Fixation of rectus sheath catheters using Steri-Strip ${ }^{\mathrm{TM}}$ skin closures to prevent accidental dislodgement. This was then covered using Tegaderm ${ }^{\mathrm{TM}}$ dressing which provides a sterile transparent covering to inspect the insertion site 
After $48 \mathrm{hr}$, the RS catheters were removed and patients were asked to rate the worst pain score at rest and with movement in the 48-hr period. They were also asked to rate overall satisfaction with pain management on a numeric scale (where $1=$ least satisfied and $10=$ most satisfied).

In case of any catheter-related infection (i.e., any tenderness or discharge at skin entry point), the patient was followed until resolution of infection. Problems such as a blocked catheter or discomfort during injection of the study drug were noted. After removal of the RS catheters, the Acute Pain Service team determined the need to continue morphine PCA and other analgesics.

\section{Statistical analysis}

The sample size calculation was based on our own experience and data from literature ${ }^{17}$ where the mean (SD) 24-hr consumption of morphine was 25.7 (9.5) $\mathrm{mg}$. Considering a $25 \%$ (6.4) $\mathrm{mg}$ reduction in morphine as clinically meaningful, a sample size of 37 in each group was required to achieve $80 \%$ power to detect a difference between the two groups with a two-sided alpha of 0.05 .

The Shapiro-Wilk test was used to assess normality of the data. All normally distributed data, including the coprimary outcome (morphine requirement in the LA group $v s$ the NS group at the end of 24 and $48 \mathrm{hr}$ ) were expressed as mean (SD) and compared between the two groups using the Student's $t$ test. All scores and non-normally distributed data were compared using the Mann-Whitney test and expressed as median [interquartile range (IQR)]. Categorical data were analyzed using the Chi square test or Fisher's exact test as appropriate.

The number of times a clinically placed needle was manipulated under ultrasound guidance was expressed as a percentage. As an exploratory secondary outcome, we assessed the accuracy of identifying the rectus space using the bimanual clinical method and included all patients randomized in the trial. As we placed RS catheters bilaterally in each patient, we analyzed 148 clinical placements in 74 trial patients.

All analysis was performed using IBM $₫$ SPSS $₫$ version 21. In view of multiple comparisons, a $P<0.004$ was considered significant (after a Bonferroni correction).

\section{Results}

From August 2 to December 2, 2013, 96 patients were assessed for inclusion in the study, and consequently, 78 patients scheduled for elective midline laparotomy in the gynecological oncology unit met the study criteria and were enrolled in the trial. Four patients were excluded intraoperatively: one patient was scheduled for elective ventilation after surgery; two patients had part of the posterior RS excised; and one patient underwent an infracolic omentectomy through a mini-laparotomy (incision only $5 \mathrm{~cm}$ ) and therefore was not included. Seventy-four patients were subsequently randomized into the LA and NS groups (Fig. 2). Both groups were comparable with respect to patient characteristics, surgical time, intraoperative opioid use, and other surgical details (Table 1). None of the patients were on long-term medication for chronic pain.

All patients completed the 24-hr observation period. The mean (SD) total morphine consumption was significantly reduced in the LA group compared with the NS group at 24 hr [8.8 (8.3) mg vs 27.3 (10.0) $\mathrm{mg}$, respectively; mean difference, $18.5 \mathrm{mg}, 95 \%$ confidence interval (CI), 14.3 to 22.8; $P<0.001]$ and at $48 \mathrm{hr}[14.8$ (11.0) $\mathrm{mg}$ vs 42.4 (16.8) $\mathrm{mg}$, respectively; mean difference, $27.7 \mathrm{mg}$; $95 \% \mathrm{CI}, 20.9$ to $34.3 ; P<0.001]$.

The RS catheter was accidentally removed at $30 \mathrm{hr}$ in one patient, and another patient needed re-exploration on day 2. In a third case, the patient complained of local site discomfort during study drug injection on postoperative day 2. There was no sign or symptom of local infection, and the RS catheters were removed. The patient was followed until discharge and she had an uneventful postoperative course (Fig. 2). Data from the above three patients were excluded from the 48-hr analysis.

There was a significant decrease in the worst median [IQR] pain scores recorded at $48 \mathrm{hr}$ at rest in the LA group compared with the NS group (3[2-3] vs 5 [5-6], respectively; $P<0.001$ ) (Fig. 3A) and with movement (4 [4-5] vs 7 [6-8], respectively; $P<0.001$ ) (Fig. 3B). The patients in the LA group ambulated earlier than patients in the NS group [9.1 (2.2) hr vs 11.9 (2.5) hr, respectively; $P<$ 0.001]. Patient satisfaction scores were also significantly better in the LA group $(P<0.001)$ (Fig. 3C).

Fifteen of the $37(41 \%)$ patients in the LA group and all 37 patients $(100 \%)$ in the NS group required additional boluses during the 48-hr period (difference in proportions, $0.59 ; 95 \% \mathrm{CI}, 0.39$ to $0.75 ; P<0.001)$. A significant reduction in nausea scores and episodes of vomiting was seen in the LA vs the NS group (Table 2). Return of bowel motility assessed by passage of flatus was significantly earlier in the LA group than in the NS group $(P<0.001)$.

The clinically guided needle placement in the rectus space was found to be inaccurate in 55 of the total 148 placements $(37 \%)$, and in each case, the needle tip had to be further manipulated under ultrasound guidance. In $6 \%$ of placements, the peritoneum was breached during the procedure, but as the insertion was performed with an open abdomen, no bowel injury was encountered. We did not encounter any infection at the catheter site. 
RESONS Trial

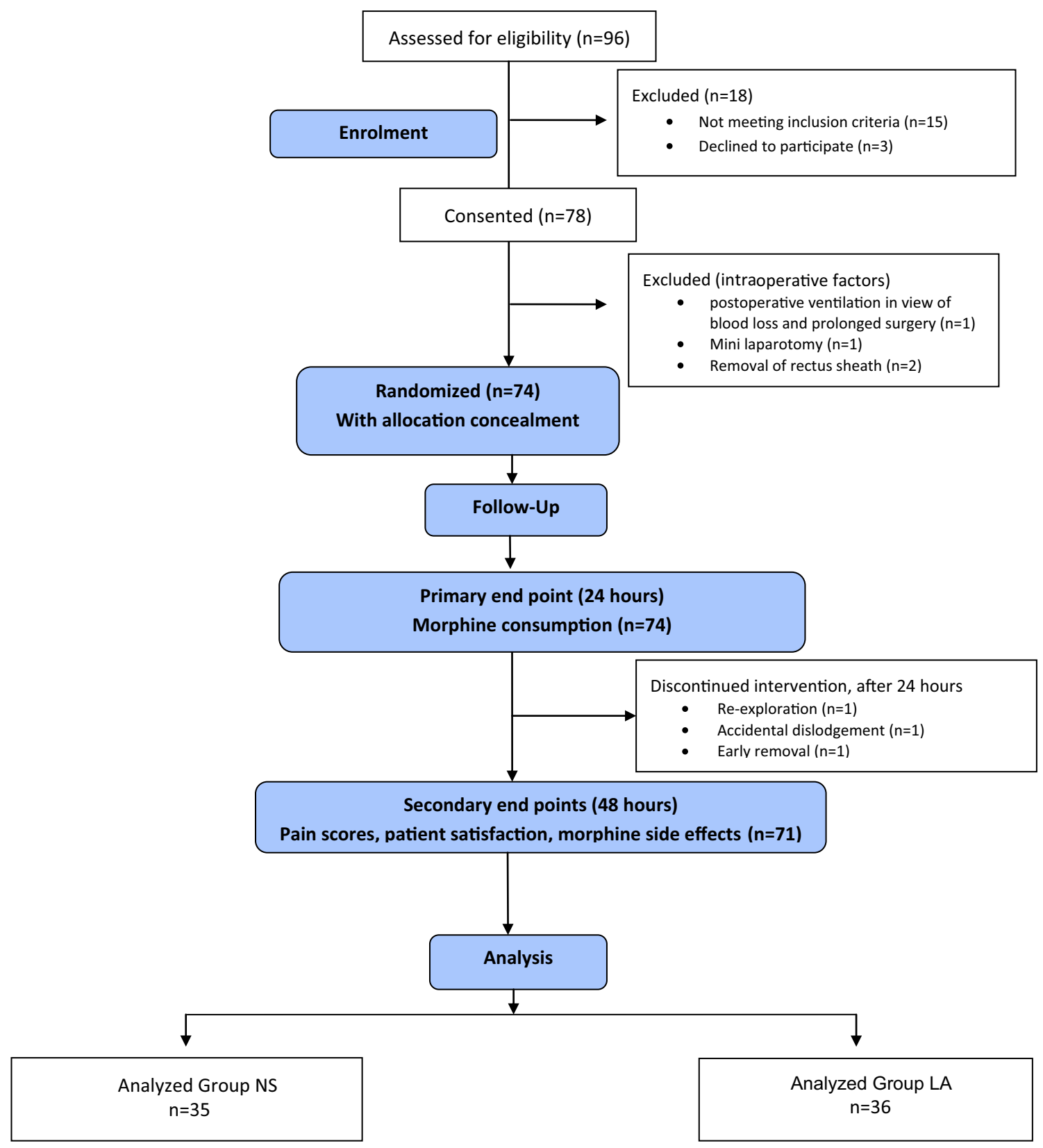

NS = Normal Saline; LA = local anesthetic

Fig. 2 Consort diagram for patient recruitment in the trial

\section{Discussion}

We found that the use of RS catheters significantly reduced pain and morphine consumption at $24 \mathrm{hr}$ and $48 \mathrm{hr}$ following gynecological cancer surgery. We also found that patients in the RS intervention arm ambulated earlier, and reported better satisfaction with the pain management. A significant improvement in morphine-associated side effects, including nausea, vomiting, and early return of bowel motility, was seen in the LA arm. Clinical placement of the needle in the rectus space using the bimanual palpation technique was initially found to be inaccurate, and $37 \%$ of total placements needed further manipulation under ultrasound guidance.

The benefits of transversus abdominis plane (TAP) block following major gynecological cancer surgery has been evaluated by Griffiths in a study using placebo $v s$ intervention. ${ }^{18}$ In that study, no difference was found in the 
Table 1 Patient demographics

\begin{tabular}{|c|c|c|c|}
\hline \multicolumn{2}{|l|}{ Variable } & $\begin{array}{l}\text { NS Group } \\
(n=37)\end{array}$ & $\begin{array}{l}\text { LA Group } \\
(n=37)\end{array}$ \\
\hline \multicolumn{2}{|l|}{ Age (yr) } & $48.8(10)$ & $47.5(10)$ \\
\hline \multicolumn{2}{|l|}{ Weight (kg) } & $55[50-65]$ & $53[48-62]$ \\
\hline \multicolumn{2}{|l|}{ Height $(\mathrm{cm})$} & $160[155-160]$ & $160[155-160]$ \\
\hline \multicolumn{2}{|l|}{$\mathrm{BMI}\left(\mathrm{kg} \cdot \mathrm{m}^{-2}\right)$} & $21[19.5-25.0]$ & $20.7[19.5-25.1]$ \\
\hline \multicolumn{2}{|l|}{ Duration of Surgery (in minutes) } & $150[120-203]$ & $150[133-183]$ \\
\hline \multirow[t]{2}{*}{ Opioids used in intraoperative period } & Fentanyl $(\mu \mathrm{g})$ & $150[100-188]$ & $150[100-200]$ \\
\hline & Morphine (mg) & $5[5-6]$ & $5[5-6]$ \\
\hline \multicolumn{2}{|l|}{ Abdominal drain } & 29 & 28 \\
\hline \multirow[t]{2}{*}{ Type of surgery } & Hysterectomy+ BSO\#+/- Omentectomy & 29 & 30 \\
\hline & Hysterectomy + BSO\#+ BPLND\#\#+/- Bowel resection & 8 & 7 \\
\hline
\end{tabular}

There was no significant difference between the two groups

Data normally distributed expressed as mean (standard deviation)

Data not normally distributed expressed as median [interquartile range]

BSO\# = bilateral salpingo-oophorectomy

BPLND\#\# = bilateral peritoneal lymph node dissection

$\mathrm{BMI}=$ body mass index; $\mathrm{LA}=$ local anesthetic group; $\mathrm{NS}=$ normal saline group

pain scores or morphine consumption between the placebo and treatment groups at $2 \mathrm{hr}$ or $24 \mathrm{hr}$ postoperatively. Nevertheless, in $28 \%$ of the study patients, the incision extended above the umbilicus, and use of the TAP block using the standard or posterior approach would have been ineffective. Our study group included similar patients undergoing a midline laparotomy for gynecological cancer. In our experience, the midline incision is often extended above the umbilicus to a varying extent. Therefore, we decided to study the role of RS catheters in these surgeries, with the added advantage of continuing the regional technique for a longer time in the postoperative period.

The 2010 Cochrane review on anterior abdominal wall blocks included five studies on TAP and three on RS blocks. ${ }^{19}$ The only study with positive benefits for the RS block was an early randomized-controlled trial (RCT) by Smith. ${ }^{20}$ Adult female patients who had undergone diagnostic laparoscopy had lower pain scores with the use of RS blocks. The review also includes an RCT by Padmanabhan et al. ${ }^{21}$ Forty patients were randomized to receive either intermittent boluses of bupivacaine $0.25 \%$ or NS via catheters clinically placed in the $\mathrm{RS}$ for $48 \mathrm{hr}$ after midline laparotomy. No reduction in pain scores or opioid requirement was found in the study group when compared with the control group. ${ }^{21}$ Their deemed cause was uneven perfusion of the infusate in the rectus space. The authors further suggested injection of contrast through the catheter to confirm spread of the drug. The Cochrane review has also highlighted the need for better evidence with respect to abdominal block localization and methodology. ${ }^{19}$ Incidentally, none of the studies used ultrasound for localization of the rectus space.
In our study, the needles were initially placed using a bimanual palpation technique ${ }^{11}$ during abdominal closure, and the accuracy of placement was then confirmed using ultrasound guidance. Incorrectly placed needles were manipulated to ensure optimal placement in all patients before abdominal closure. This study was so designed to understand the accuracy of clinically placed needles and the need for ultrasound guidance, as intraoperative ultrasound may not be easily available to anesthesiologists practicing at centres with limited resources. A need to manipulate $37 \%$ of the catheter placements suggests that bimanual placement of the needle in the rectus space may not be accurate at all times. The use of ultrasound helped confirm correct catheter placement by visualizing the uniform spread of the infusate between the rectus muscle and posterior RS -similar findings have been reported in the literature. $^{15,22}$

The proximity of the posterior RS to the peritoneal cavity can easily lead to needle misplacement and intraperitoneal injection. $^{23}$ Liver injury has been reported following ultrasound-guided abdominal blocks. ${ }^{24}$ With the aim of examining the accuracy of clinically placed needles, we adopted the technique of ultrasound localization of the rectus space with an open abdomen. We found this to be a safe technique with no procedure-related serious adverse effects. Though we had peritoneal breach in $6 \%$ of cases, as we had performed the needle insertion with an open surgical wound, there were no cases of accidental bowel penetration, and the needles were repositioned successfully. Ultrasoundguided placement with an open abdomen thus has the advantage of assured placement with no complications. 
(a)

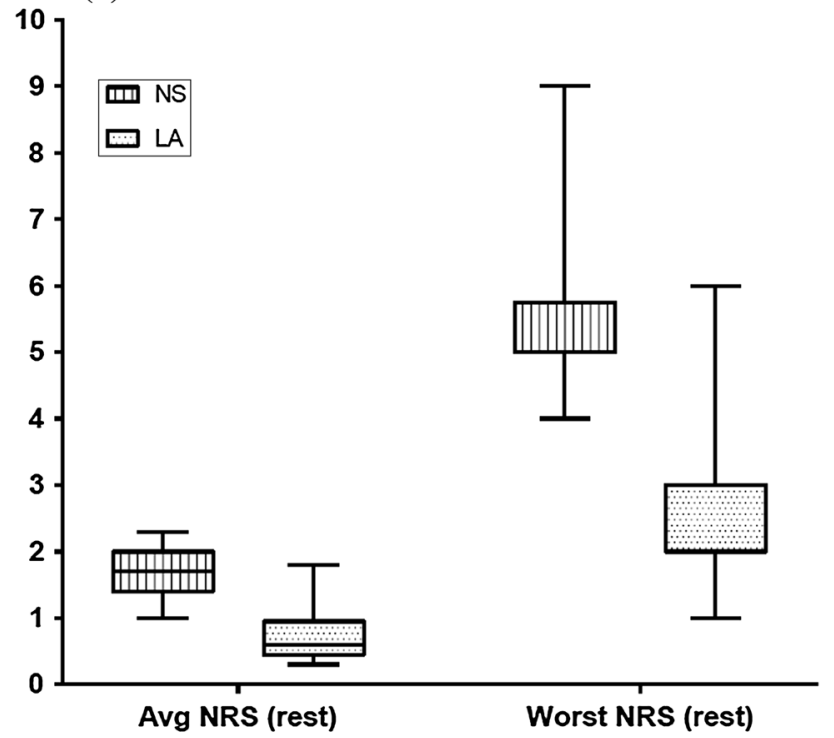

(b)

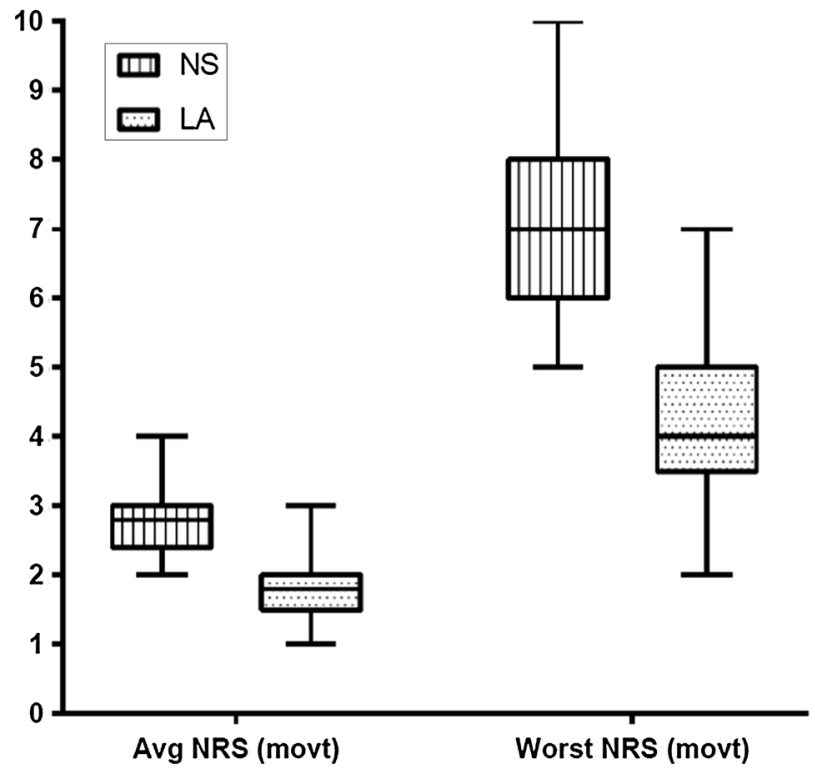

Fig. 3 A Box plot comparing the pain scores at rest. NRS scale was used (10- worst pain experienced). The Avg NRS (rest) and worst NRS (rest) were significantly lower in the Local anesthetic (LA) group ( $\mathrm{p}<0.001$ for each comparison). B Box plot comparing the pain scores with movement. NRS scale was used (10- worst pain

Opioids alone may not provide optimum dynamic pain relief after a major procedure ${ }^{25}$; which explains the significant difference in pain scores in the LA arm. The large difference in morphine consumption is potentially explained by the relatively high-risk patients undergoing surgery. We found a significant reduction in the incidence of nausea and vomiting, with an early return of bowel motility in the LA arm, emphasizing the effectiveness of (c)

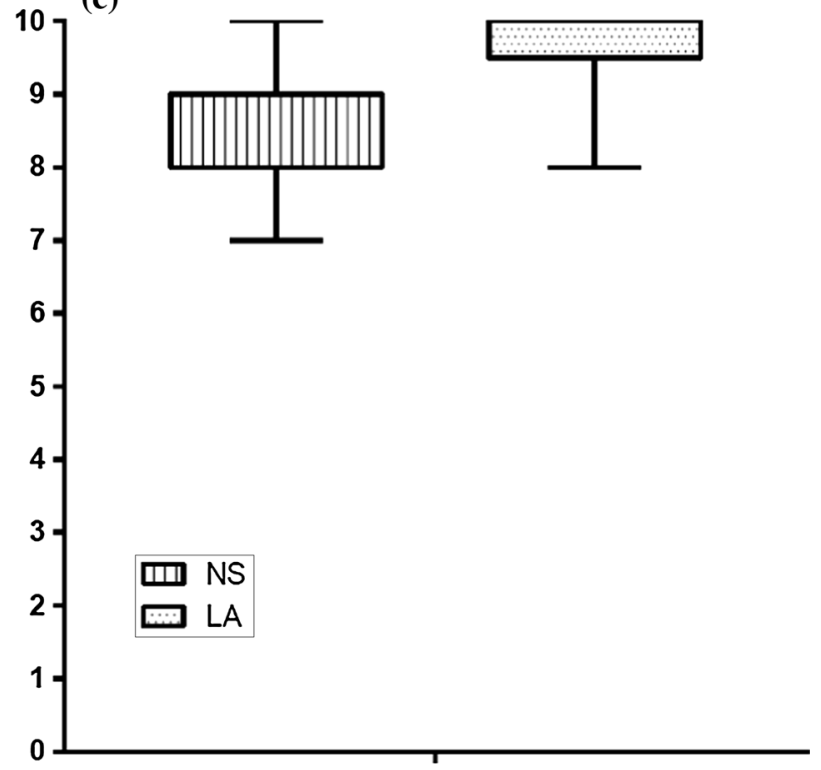

Patient Satisfaction experienced). Avg NRS (movt) and Worst NRS (movt) were significantly lower in the Local anesthetic (LA) group $(p<0.001$ for each comparison). C Box plot comparing patient satisfaction with the pain management between the two groups Satisfaction was recorded on score of 1-10 (10- most satisfied); $\mathrm{p}<0.001$

the RS block as an opioid-sparing pain management technique.

There were some limitations to our study. One limitation is that the RS catheters were placed at the end of the case and hence could not be used intraoperatively. In general, RS catheters can be placed at the beginning before the surgical incision, ${ }^{11}$ which might help reduce subsequent intraoperative use of opioids. Second, this study looked at 
Table 2 Comparison of opioid-related side effects at $48 \mathrm{hr}$

\begin{tabular}{|c|c|c|c|c|}
\hline & & $\begin{array}{l}\text { NS Group, } \\
n=35\end{array}$ & $\begin{array}{l}\text { LA Group, } \\
n=36\end{array}$ & $P$ value \\
\hline \multicolumn{2}{|c|}{ Median Nausea score* [IQR] } & $3[2-4]$ & $2[1-3]$ & $<0.001$ \\
\hline \multicolumn{2}{|c|}{ Episodes of vomiting [IQR] } & $3[1-4]$ & $0[0-2]$ & $<0.001$ \\
\hline \multicolumn{2}{|l|}{ Sedation score\# [IQR] } & $2[2-3]$ & $2[2-2]$ & 0.01 \\
\hline \multirow[t]{2}{*}{ Flatus passed } & Yes & $6(17 \%)$ & $33(92 \%)$ & $<0.001$ \\
\hline & Difference in proportion $\%(95 \% \mathrm{CI})$ & $75(54$ to 85$)$ & & \\
\hline \multirow[t]{2}{*}{ Incidence of Itching } & Yes & $6(17 \%)$ & 0 & 0.02 \\
\hline & Difference in proportion $\%(95 \% \mathrm{CI})$ & 17 (4 to 33$)$ & & \\
\hline
\end{tabular}

$\mathrm{CI}=$ confidence interval; $\mathrm{IQR}=$ interquartile range; $\mathrm{LA}=$ local anesthetic group; $\mathrm{NS}=$ normal saline group

* Nausea score using numeric rating scale $(0=$ absent; $10=$ extreme)

\# As per Ramsay sedation scale ( $1=$ awake, anxious, agitated, restless and $6=$ asleep, no response to light glabellar tap or loud auditory stimulus $)$

the benefit of RS catheters only in the immediate postoperative period; their impact on chronic pain was not studied.

In conclusion, administration of intermittent boluses of local anesthetic through ultrasound-guided RS catheters is an effective morphine-sparing analgesic technique in the first 24-48 $\mathrm{hr}$ postoperatively for females undergoing a midline laparotomy for gynecological cancer. Early ambulation, lower pain scores, reduction in the incidence of nausea and vomiting with early return of bowel activity are the added benefits of this intervention.

Acknowledgements The authors are grateful to Dr. R. Kerkar MD, Professor and Head of the Gynecological Oncology Department, and Dr. J.V. Divatia MD, Professor and Head of the Department of Anesthesia, Critical Care and Pain, Tata Memorial Hospital, Mumbai, India, for their support in conducting the trial. We sincerely thank Drs B. Nagarkarand and U. Dhundi, Registrars, Department of Anesthesia, Critical Care and Pain, Tata Memorial Hospital, Mumbai, India for their invaluable support in the randomization and study drug preparation. We are also grateful to Mrs S. Kannan, MSc, Data Manager, ACTREC, Tata Memorial Hospital, Mumbai, India for her advice and help in the analysis of data.

Conflicts of interest None declared.

Author contributions Sumitra G. Bakshi and T.S. Shylasree contributed to the concept of the study. Sumitra G. Bakshi, Amol Mapari, and T.S. Shylasree contributed to the study design, analysis and interpretation of data, and preparation of the final draft. Sumitra G. Bakshi and Amol Mapari contributed to the acquisition of data.

Editorial responsibility This submission was handled by Dr. Hilary P. Grocott, Editor-in-Chief, Canadian Journal of Anesthesia.

\section{References}

1. Kehlet $H$. Enhanced recovery after surgery (ERAS): good for now, but what about the future? Can J Anesth 2015; 62: 99-104.
2. Tan M, Law LS, Gan TJ. Optimizing pain management to facilitate enhanced recovery after surgery pathways. Can J Anesth 2015; 62: 203-18.

3. Gustafsson UO, Scott MJ, Schwenk W, Enhanced Recovery After Surgery Society, et al. Guidelines for perioperative care in elective colonic surgery: Enhanced Recovery After Surgery (ERAS $\AA$ ) Society recommendations. Clin Nutr 2012; 31: 783-800.

4. Dutton TJ, McGrath JS, Daugherty MO. Use of rectus sheath catheters for pain relief in patients undergoing major pelvic urological surgery. BJU Int 2014; 113: 246-53.

5. Marret E, Remy C, Bonnet F, Postoperative Pain Forum Group. Meta analysis of epidural analgesia versus parenteral opioid analgesia after colorectal surgery. Br J Surg 2007; 94: 665-73.

6. Schug SA, Kehlet H, Bonnet F, et al. Procedure specific pain management after surgery-"PROSPECT". Acute Pain 2007; 9: 55-7.

7. Marhofer $P$, Greher $M$, Kapral $S$. Ultrasound guidance in regional anaesthesia. Br J Anaesth 2005; 94: 7-17.

8. Shido A, Imamachi N, Doi K, Sakura S, Saito Y. Continuous local anesthetic infusion through ultrasound guided rectus sheath catheters. Can J Anesth 2010; 57: 1046-7.

9. Bakshi S, Mapari A, Paliwal R. Ultrasound-guided rectus sheath catheters: a feasible and effective, opioid- sparing, post-operative pain management technique: a case series. Indian J Anaesth 2015; 59: $118-20$.

10. Godden AR, Marshall MJ, Grice AS, Daniels IR. Ultrasonography guided rectus sheath catheters versus epidural analgesia for open colorectal cancer surgery in a single centre. Ann R Coll Surg Engl 2013; 95: 591-4.

11. Finch L, Phillips A, Acheson N, Dix P, Berry C. An evaluation of the effects of a service change from epidurals to rectus sheath catheters on postoperative pain. J Obstet Gynaecol 2013; 33: 502-4.

12. Crosbie EJ, Massiah NS, Achiampong JY, Dolling S, Slade RJ. The surgical rectus sheath block for post-operative analgesia: a modern approach to an established technique. Eur J Obstet Gynecol Reprod Biol 2012; 160: 196-200.

13. Hjermstad MJ, Fayers PM, Haugen DF, et al. European Palliative Care Research Collaborative (EPCRC). Studies comparing numeric rating scales, verbal rating scales, and visual analogue scales for assessment of pain intensity in adults: a systematic literature review. J Pain Symptom Manage 2011; 41: 1073-93.

14. Merchant $R$, Chartrand D, Dain $S$, et al. Guidelines to the practice of anesthesia-revised edition 2016. Can J Anesth 2016; 63: 86-112. 
15. Sandeman DJ, Dilley $A V$. Ultrasound-guided rectus sheath block and catheter placement. ANZ J Surg 2008; 78: 621-3.

16. McGrane $S$, Pandharipande PP. Sedation in the intensive care unit. Minerva Anestesiol 2012; 78: 369-80.

17. Unlugenc H, Vardar MA, Tetiker S. A comparative study of the analgesic effect of patient-controlled morphine, pethidine, and tramadol for postoperative pain management after abdominal hysterectomy. Anesth Analg 2008; 106: 309-12.

18. Griffiths JD, Middle JV, Barron FA, Grant SJ, Popham PA, Royse $C F$. Transversus abdominis plane block does not provide additional benefit to multimodal analgesia in gynaecological cancer surgery. Anesth Analg 2010; 111: 797-801.

19. Charlton S, Cyna AM, Middleton P, Griffiths JD. Perioperative transversus abdominis plane (TAP) blocks for analgesia after abdominal surgery. Cochrane Database Syst Rev 2010; 12: CD007705.

20. Smith BE, Suchak M, Siggins D, Challands J. Rectus sheath block for diagnostic laparoscopy. Anaesthesia 1988; 43: 947-8.
21. Padmanabhan J, Rohatgi A, Niaz A, Chojnowska E, Baig K, Woods WG. Does rectus sheath infusion of bupivacaine reduce postoperative opioid requirement? Ann R Coll Surg Engl 2007; 89: 229-32.

22. Dolan J, Lucie P, Geary T, Smith M, Kenny G. The rectus sheath block for laparoscopic surgery in adults: a comparison between the loss of resistance and ultrasound guided techniques. Anesthesia 2007; 62: 301-13.

23. Willschke H, Bosenberg A, Marhofer P, et al. Ultrasonographyguided rectus sheath block in paediatric anaesthesia- a new approach to an old technique. Br J Anaesth 2006; 97: 244-9.

24. Lancaster $P$, Chadwick $M$. Liver trauma secondary to ultrasoundguided transversus abdominis plane block. Br J Anaesth 2010; 104: 509-10.

25. Kehlet $H$, Holte $K$. Effect of postoperative analgesia on surgical outcome. Br J Anaesth 2001; 87: 62-72. 